Part of Journal of Research of the National Bureau of Standards, Volume 18, May 1937

\title{
PREPARATION OF IRON OXIDE AS A SOURCE OF HIGH- PURITY IRON
}

\author{
By Harold E. Cleaves and John G. Thompson
}

\begin{abstract}
Selected ferric nitrate has been purified by recrystallization, yielding several lots of iron oxide of high purity. Examination of the products by spectrochemical and chemical methods, for the presence of 51 possible impurities, shows that silicon is the principal impurity in each of the oxides; in the best materials the silicon content is 0.005 or 0.006 percent. Four additional elements, aluminum, calcium, magnesium, and copper are present, but the sum of these four is less than 0.001 percent of each sample.

These oxides have been prepared as a preliminary step in the preparation of metallic iron of high purity.
\end{abstract}

\section{CONTENTS}

I. Introduction

II. Review of methods for the preparation of high-purity iron

III. Investigation of methods for the preparation of purified compounds of iron

1. Ferrous-oxalate method

2. Ferrous-formate method

3. Ferrous-chloride method

4. Ferrous-sulphate method

5. Ferric-nitrate method_..._.

6. Combined ferrous-chloride and ferric-nitrate method

7. Cupferron method ...... 602

8. Summary of available methods_...

IV. Production of high-purity ferric oxide

V. Selected references_._._.

\section{INTRODUCTION}

One of the functions of the Metallurgical Division of the National Bureau of Standards is to compile available information on the preparation and properties of metals and alloys, particularly those of unusual purity. Previous activity in this field has resulted in the publication of several circulars, each dealing with one of the following metals and its alloys: copper, nickel, aluminum and magnesium, bismuth, zinc, and silver. The current study is concerned with the metal iron and consists in two phases (1) a review of available information from the technical literature, and (2) the preparation in the laboratory of iron of high purity and of definitely known composition. The first phase of the work has been completed, the results being published in the form of a monograph[15] ${ }^{1}$ and summarized in another publication [16]. The present report describes the preparation of purified iron oxide, the first stage in the laboratory preparation of metallic iron of high purity.

\footnotetext{
1 The numbers in brackets here and throughout the text refer to the list of selected references at the end of the paper.
} 


\section{REVIEW OF METHODS FOR THE PREPARATION OF HIGH-PURITY IRON}

Available information indicates that the best product obtainable by the smelting of an iron ore with subsequent refining in the molten state is iron of about 99.8-percent purity. ${ }^{2}$ Methods employed in the past for the preparation of iron of higher purity than this have been of two general types, electrolytic and chemical. Recently iron of high purity has been prepared by the cyclic formation and decomposition of iron carbonyl, but available information regarding this process is limited. Since the claim of extraordinary purity in the product has not yet been substantiated, and as elaborate apparatus is required for operating under high pressures and at elevated temperatures, the carbonyl process was eliminated from consideration in the present work. Sublimation processes likewise were eliminated from consideration because of manipulative difficulties and also because the recent work of Kroll not produce a satisfactory separation of iron from its associated impurities.

Records of the numerous investigations of electrolytic processes indicate that the best electrolytic irons were of somewhat higher purity than is obtainable by smelting and refining operations but, nevertheless, were not pure irons. Certain impurities, particularly nickel, were always present. None of the electrolytic processes yielded iron of as high purity as has been obtained for other electrolytic metals, zinc, aluminum, and lead, for example. The conclusion that the possibilities of electrolytic methods for the production of very pure iron were limited, was based upon the records of the many investigations of electroly tic iron during the period from 1910 to 1920 , when interest in this product was highest. However, this conclusion has been confirmed by the results of a recent investigation of electrolytic iron at the National Physical Laboratory in England, according to the report of Adcock and Bristow [14].

Chemical methods involving the preparation of a purified compound of iron with subsequent reduction to the metal were used for the laboratory production of two irons, by Lambert and Thomson [7] and by Baxter and Hoover [8], that were probably the purest ever prepared. For this reason, and because of the difficulties and apparent limitations of the carbonyl and electrolytic processes, attention in the present investigation was concentrated on chemical methods.

Two distinct stages are involved in chemical methods for the preparation of high-purity iron (1) preparation of a purified compound of iron, and (2) conversion of the purified compound to metallic iron, by reduction and sintering (or melting). The greatest possible purity in the purified compound is essential as experience has shown that the subsequent conversion to metallic iron introduces contamination more often than it removes impurities. The present paper is concerned only with the preparation of a purified salt of iron. The conversion of this compound to metallic iron will be discussed in a subsequent paper.

${ }^{2}$ For detailed discussion of the various methods of producing iron of high purity, see references [15] and [16 . 


\section{INVESTIGATION OF METHODS FOR THE PREPARA- TION OF PURIFIED COMPOUNDS OF IRON}

Most of the attempts to prepare a very pure salt of iron have involved precipitation and recrystallization of compounds such as the oxalate, formate, chloride, sulphate, and nitrate. The usual practice has been to convert the purified compound to the oxide as the last step prior to reduction, and the ultimate goal in the preparation of a pure compound of iron is therefore the production of pure iron oxide. The latter compound, however, cannot be prepared directly from an impure source; the conversion to iron oxide is not in itself an efficient purification process. Consequently, the preparation of some other pure compound of iron is necessary as an intermediate step in the preparation of pure iron oxide.

Previous attempts to purify various compounds, and some results obtained in the present investigation, are briefly reviewed in the ensuing paragraphs.

\section{FERROUS-OXALATE METHOD}

Precipitation of crystalline ferrous oxalate from aqueous solutions was one of the first recorded methods for freeing iron from its associated impurities. Matthiessen and Szczepanowski [1] studied this compound prior to 1870; subsequently Dragendorff [2], McGillivray [3], Kreusler [6], and workers at the Physikalisch-Technische Reichsanstalt [5] investigated its preparation. The usual practice was to ignite the purified oxalate to form the oxide, which was subsequently reduced with hydrogen. Kreusler estimated that some iron which he prepared from ferrous oxalate was of very high purity; the metal was malleable and resistant to hydrochloric acid but dissolved readily in nitric acid. However, no analysis was given and some of the reported properties do not indicate exceptional purity. In the 1908 report of the extended work at the Physikalisch-Technische Reichsanstalt it was concluded that ferrous oxalate invariably contained manganese and other metallic constituents. McGillivray called attention to the fact that iron oxide prepared by ignition of ferrous oxalate was usually contaminated by carbon, and this was confirmed by the recent work of Sykes [10].

In the present investigation the starting material was reagentgrade ferrous sulphate in which the ratio of $\mathrm{Mn}$ to $\mathrm{Fe}$ was 0.134 to 100. Ferrous-oxalate crystals precipitated from a solution of this material by additions of oxalic acid or ammonium oxalate always contained manganese, usually about as much as the original sulphate. Fractional precipitation of ferrous oxalate did not result in concentration of the manganese in any one fraction, instead, it was distributed fairly uniformly in all fractions. Spectrochemical examination of oxide obtained by ignition of some of the oxalate crystals showed that small amounts of $\mathrm{Al}, \mathrm{Si}$, and $\mathrm{Ni}$ and somewhat larger amounts of $\mathrm{Mg}, \mathrm{Ca}$, and $\mathrm{Cr}$ were present in addition to the manganese.

The presence of appreciable amounts of so many metallic elements, the probable presence of carbon, and the evidence of previous workers indicate that the oxalate method is not promising for the preparation of very pure iron oxide. 


\section{FERROUS-FORMATE METHOD}

The precipitation of ferrous formate is mentioned in the reports of the Physikalisch-Technische Reichsanstalt [5] as having the same disadvantages as the ferrous-oxalate method, particularly in the failure to eliminate manganese and other impurities. To confirm this conclusion, ferrous formate was precipitated by additions of formic acid to a solution of ferrous sulphate, with additions of ammonia to maintain approximate neutrality in the solution. The yield was small and spectrochemical examination showed the presence of comparable amounts of the same impurities that were found in the oxalate crystals. The ferrous-formate method did not appear to be promising.

\section{FERROUS-CHLORIDE METHOD}

The precipitation of ferrous-chloride crystals from aqueous solutions by additions of concentrated hydrochloric acid was considered by McGillivray [3] to be an improvement over the oxalate method. Richards and Baxter [4] used ferrous chloride as the starting material in their determination of the atomic weight of iron but converted the chloride to other salts of iron for further purification. Aqueous solutions of ferrous chloride were frequently used as electrolytes in the preparation of iron, but the purity of the electrolyte was seldom a matter of particular concern; the process of electrolysis was assumed to eliminate minor impurities either present in the original electrolyte or introduced by solution of the iron anode. In recent work at the National Physical Laboratory $[12,13,14]$ in England, it was concluded that contamination of electrolytic iron by nickel, cobalt, and copper could not be avoided, and that iron of higher purity could be prepared by decomposing purified ferrous chloride with steam and reducing the resulting ferric oxide with hydrogen. A complete description of the preparation of this purified ferrous chloride is not yet available.

In the present investigation crystals were precipitated from aqueous solutions of ferrous chloride of reagent grade, either by chilling the solution or by pouring it into concentrated hydrochloric acid. In either case the crystals were redissolved and reprecipitated several times, but spectrochemical examination of the final products showed that appreciable amounts of manganese were present in addition to several other metallic impurities. These results, together with the low yields of crystals obtained, indicated that recrystallization of of ferrous chloride was not suitable for our purposes.

\section{FERROUS-SULPHATE METHOD}

Decomposition of reagent-grade ferrous sulphate by fusion with sodium sulphate and reduction of the resulting oxide with hydrogen was reported to be the best of four methods studied by Matthiessen and Szczepanowski [1]. Aqueous solutions of ferrous or ferrousammonium sulphate were frequently used in the electrodeposition of iron, but as in the case of the ferrous-chloride electrolytes, the purity of the ferrous-sulphate solution was seldom a matter of concern. The solutions usually were prepared from commercial irons and retained the impurities thereof. When purified salts were used to prepare the original electrolyte, the solution was soon contaminated in use by impurities from the soluble anodes. However, Richards and Baxter [4] employed electrolysis of a ferrous-sulphate-ammonium-oxalate 
solution as one of the intermediate steps in their preparation of a pure compound for the determination of the atomic weight of iron.

In the present investigation little attention was devoted to recrystallization of sulphates, primarily because of the known difficulty of obtaining a sulphur-free product from such a source and the objectionable nature of this element as an impurity in iron. Furthermore, examination of reagent-grade materials showed that both ferrous sulphate and ferrous-ammonium sulphate contained appreciable amounts of manganese and other metallic impurities.

\section{FERRIC-NITRATE METHOD}

Recrystallization of ferric nitrate $\left(\mathrm{Fe}\left(\mathrm{NO}_{3}\right)_{3} .9 \mathrm{H}_{2} \mathrm{O}\right)$ was used by Richards and Baxter [4] as the final stage in the purification of iron compounds prior to conversion to the oxide for atomic-weight determinations. In an extended investigation at the Physikalisch-Technische Reichsanstalt [5] it was concluded that recrystallization of ferric nitrate constituted the best available method for the preparation of a very pure salt of iron. Lambert and Thomson [7] and Baxter and Hoover [8] used this method to prepare purified salts of iron, and the metallic iron eventually obtained in these two investigations was probably the best ever made. From these results, obtained by previous workers, crystallization of ferric nitrate seemed worthy of careful study in the present investigation.

Ferric nitrate, because of its large content of water and low melting point, is not a satisfactory compound for reduction and for spectrochemical examination. One of the first considerations, therefore, was the procedure to be used in converting ferric nitrate to a more suitable compound. Lambert and Thomson [7] and Baxter and his coworkers $[4,8]$ heated or ignited ferric nitrate and obtained products variously described as ferric oxide or a mixture of the oxide and basic nitrate. In the work at the Physikalisch-Technische Reichsanstalt [5], ferric nitrate was heated to $50^{\circ} \mathrm{C}$, melting in its own water of crystallization. Anhydrous ammonia was passed into the melt, forming ferric oxide and ammonium nitrate. After cooling the latter compound was removed by washing witb water. Attempts to duplicate this procedure in the present investigation were not successful. A large amount of heat was evolved by the reaction between ammonia and ferric nitrate, and the resulting evaporation of water thickened the mixture to a hard mass, which frequently plugged the ammonia delivery tube. Additions of water resulted in the formation of basic ferric nitrate without improving the operation. The conversion of nitrate to oxide was never complete in our experiments; the product invariably was a mixture of oxide and basic nitrate.

Precipitation of hydrated ferric oxide by additions of gaseous ammonia to a dilute solution of ferric nitrate in distilled water, washing the precipitate by decantation to free it from nitrate, and finally filtering and drying, appeared to be a decided improvement over earlier procedures for obtaining uncontaminated ferric oxide. Precipitation from dilute aqueous solution, therefore, was employed throughout the present investigation for the conversion of ferric nitrate to the oxide.

Ferric nitrate is so soluble in water that its recrystallization from this medium is difficult and inefficient. When only $125 \mathrm{ml}$ of water 
was added to $1,000 \mathrm{~g}$ of ferric nitrate $\left.\left(\mathrm{FeNO}_{3}\right)_{3} .9 \mathrm{H}_{2} \mathrm{O}\right)$ and the resulting solution was chilled to $15^{\circ} \mathrm{C}$, only about 70 percent of the ferric nitrate crystallized from the solution. The crystals so obtained were redissolved and reprecipitated and the process was repeated through five successive crystallizations. Examination of the products showed that manganese, present in the original material to the extent of 0.0047 percent, was materially reduced by the first crystallization and could not be detected in the products of the fourth and fifth crystallizations. The number and amounts of the other metallic impurities, determined by spectrochemical examination, were less than in the methods previously investigated. Recrystallization of ferric nitrate, therefore, appeared to be promising as a purification process, particularly for the elimination of manganese, which is not removed by the other methods. However, the yield obtained in crystallization from aqueous solutions was low; only 29 percent of the original material was recovered after four crystallizations. Consequently, attention was turned to the possibility of crystallizing ferric nitrate from other media.

Crystallization from solution in concentrated nitric acid was found to be impracticable as the crystallization was difficult to induce and at best proceeded at a very slow rate. Much better results were obtained with a medium consisting of 10 volumes of concentrated nitric acid and 1 volume of distilled water. $1,000 \mathrm{~g}$ of ferric-nitrate crystals of reagent grade dissolved readily in $450 \mathrm{ml}$ of this 10:1 nitric acid at 50 or $60^{\circ} \mathrm{C}$. If this solution was cooled to $15^{\circ} \mathrm{C}$ about 90 percent of the ferric nitrate separated out as crystals. Somewhat higher recoveries were obtained when the solution was cooled to temperatures below $15^{\circ} \mathrm{C}$; on the other hand, noticeably lower recoveries were obtained at temperatures above $15^{\circ} \mathrm{C}$. Consequently, all crystallizations from 10:1 nitric acid were conducted at $15^{\circ} \mathrm{C}$, or below.

A series of crystallizations from this medium was carried out. Each crop of crystals was separated from the mother liquor and, after drying in a Büchner funnel with suction, was then available for resolution and recrystallization. The proportions of $450 \mathrm{ml}$ of $10: 1$ acid to $1,000 \mathrm{~g}$ of ferric-nitrate crystals were maintained in all of the solutions. Spectrochemical examination of samples of ferric oxide derived from this series of crystallizations showed that the higher yields obtained by crystallization from 10:1 nitric acid, as compared with aqueous solutions, did not involve a sacrifice of purity in the product. Chromium persisted through six crystallizations, but the elimination of manganese was complete in two crystallizations.

The other impurities in the recrystallized ferric nitrate consisted chiefly of small amounts of aluminum, calcium, magnesium, and silicon. The amounts of these constituents varied in an irregular manner from one crystallization to the next, which indicated that they were being replenished from time to time. Two possible sources of contamination were considered: (1) Nonvolatile matter in the nitric acid and (2) dust and particles of fly ash in the laboratory atmosphere. Concentrated nitric acid was found to contain nonvolatile matter to the extent of only 0.0004 percent by weight, which presumably indicated slight solvent action of the concentrated acid on the soft-glass bottles in which it was stored. However, a relatively large volume of acid is used in a series of crystallizations and the cumulative effect of even these amounts of impurities might be appreciable. When 
the same acid was distilled in Pyrex it still contained a trace of volatile solids, presumably ammonium salts, but the nonvolatile residue from $50 \mathrm{ml}$ of distillate was too small to be weighable, certainly less than 0.0001 percent by weight. The possibility of contamination from the nitric acid therefore is slight, particularly if the acid is freshly distilled.

Contamination by dust particles was avoided during most of the crystallization process by conducting the operations in covered containers. However, in the filtration and drying of the nitrate crystals, large volumes of air were drawn through the precipitate. To avoid the possibility of contamination in this operation the apparatus shown in figure 1 was constructed. With this arrangement the air supplied to the filter was previously cleaned by passage through filter paper.

Recrystallization of ferric nitrate from a strongly acid solution appears to be the most promising method so far investigated; except for its failure to eliminate chromium.

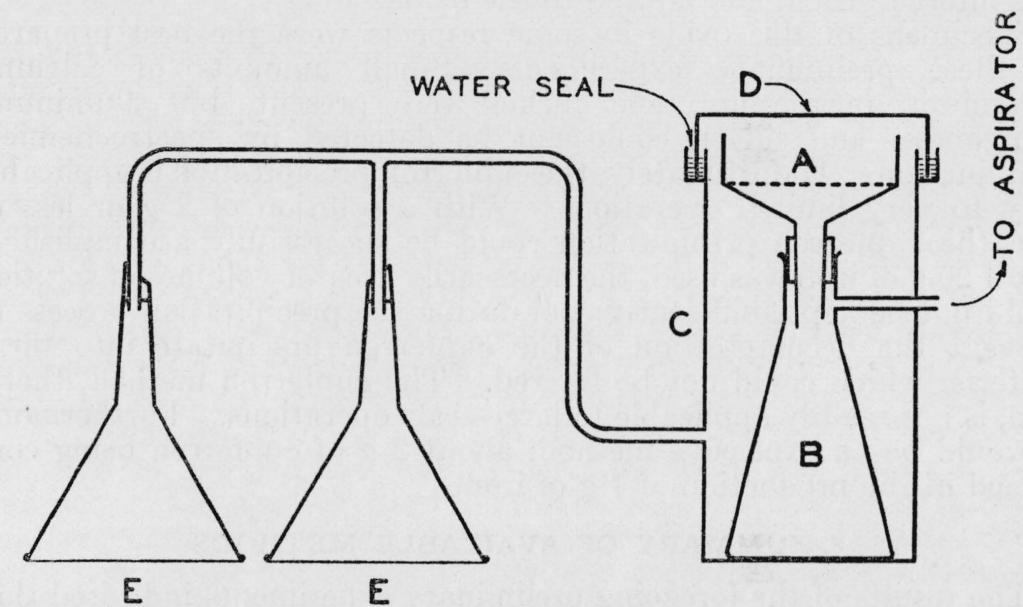

FIGURE 1.-Dustproof filtering apparatus

$A$, Büchner funnel (10 in.); $B$, filter flask; $C$, sheet-iron container; $D$, glass cover; $E$, filter paper (Whatman no. 2) cemented to lip of glass funnel (12 in.).

\section{COMBINED FERROUS-CHLORIDE AND FERRIC-NITRATE METHOD}

The products of the ferrous-chloride crystallizations contained manganese but were free from chromium; the products of nitrate crystallizations contained chromium but no manganese. Therefore, it appeared possible that a combination of the two methods would eliminate both impurities. Accordingly, ferrous chloride from several sources was crystallized twice and the product was converted to ferric nitrate which was crystallized twice. Spectrochemical examination of the final products showed that the combination method eliminated chromium but otherwise had no advantages over the straight nitrate method. Furthermore, the combination method was difficult and tedious in its manipulation and the yield was only about 30 percent. If chromium-free starting material were available the nitrate method would be decidedly preferable to the combined chloride-nitrate procedure. 


\section{CUPFERRON METHOD}

In one of the procedures of analytical chemistry, the reagent cupferron is employed to separate iron from certain elements after interfering elements have been removed from the solution. To investigate the purity of this product an aqueous solution of ferrous sulphate (reagent grade) was slightly acidified with sulphuric acid and was treated with hydrogen sulphide to precipitate the heavy metals. The precipitate was removed by filtration, the filtrate was made ammoniacal, tartaric acid added, and the solution again treated with hydrogen sulphide, this time to precipitate the iron, nickel, cobalt, zinc, and a part of the manganese present. The precipitate was dissolved in hydrochloric acid, nitric acid added, and the solution oxidized by boiling. Perchloric acid was added and the solution evaporated to fumes to dehydrate silica. The residue was diluted and filtered. The acidity of the filtrate was adjusted and the iron precipitated from the chilled solution with cupferron. The precipitate was filtered, dried, and ignited to the oxide.

Specimens of this oxide in some respects were the best prepared in these preliminary experiments. Small amounts of calcium, chromium, magnesium, and nickel were present, but aluminum, manganese, and silicon could not be detected by spectrochemical examination. Unfortunately, the cupferron precipitation is applicable only to very limited operations. With a solution of $2 \mathrm{~g}$ or less of iron the cupferron precipitation could be successfully accomplished, but if $20 \mathrm{~g}$ of iron was used, the necessarily greater volumes of solution could not be kept sufficiently cool during the precipitation process to prevent the decomposition of the cupferron precipitate into tarry material which could not be filtered. The cupferron method, therefore, is not readily applicable to large-scale operations. Furthermore, it would be an expensive method, about $2 \mathrm{~g}$ of cupferron being consumed in the production of $1 \mathrm{~g}$ of iron.

\section{SUMMARY OF AVAILABLE METHODS}

The results of the foregoing preliminary experiments indicated that recrystallization of ferric nitrate from a nitric-acid solution was the most promising method for the preparation of an iron compound containing the least number and smallest amounts of impurities. The principal impurity in the nitrate crystals was chromium, and the elimination of this element apparently could be accomplished only by starting with ferric nitrate prepared from a chromium-free material such as electrolytic iron.

\section{PRODUCTION OF HIGH-PURITY FERRIC OXIDE}

Raw material for the production of purified ferric oxide consisted of about 135 pounds of electrolytic iron, chiefly miscellaneous scrap from the work on electrolytic iron at this Bureau about 20 years ago [9]. The conversion of this material into one large, uniform lot of ferric nitrate, with one or two recrystallizations of the entire mass, followed by recrystallizations on a small scale in the laboratory, using freshly distilled acid and the dustproof filtering apparatus, should produce ferric oxide of uniform composition and high purity.

The aid of a producer of commercial chemicals was enlisted for the bulk conversion of the raw material and for the large-scale recrystal- 
lizations. To determine the purification obtainable in commercial operations a pilot run was made at the commercial plant, converting a small lot of iron to nitrate with two subsequent crystallizations. The pilot run produced about 10 pounds of ferric-nitrate crystals. Spectrochemical examination of a representative sample, after conversion to the oxide, indicated that a very satisfactory degree of purity had been attained with two recrystallizations and that further recrystallizations on a large scale were unnecessary. The entire supply of electrolyticiron scrap was therefore converted to ferric nitrate and recrystallized twice in the commercial plant, producing 306 pounds of purified crystals and 144 pounds of secondary crystals recovered from the mother liquor. The recovery of purified crystals from the large-scale operations was decidedly less than had been previously obtained in our operations on a laboratory scale.

A composite sample of the commercially purified crystals was recrystallized twice in the laboratory, using freshly distilled nitric acid and the dustproof filter. Portions of the original material and of the product of each recrystallization were converted to ferric oxide. Examination of the arc spectrum of these samples of oxide, using copper electrodes, indicated that impurities were present as follows:

\begin{tabular}{|c|c|c|c|}
\hline Element & $\begin{array}{l}\text { Commer- } \\
\text { cially puri- } \\
\text { fied }\end{array}$ & $\begin{array}{l}\text { First recrys- } \\
\text { stallization }\end{array}$ & $\begin{array}{l}\text { Second re- } \\
\text { crystalliza- } \\
\text { tion }\end{array}$ \\
\hline $\begin{array}{l}\mathrm{Si} \\
\mathrm{Ca} \\
\mathrm{Al} \\
\mathrm{Mg}\end{array}$ & $\begin{array}{l}\text { Weak } \\
\text { Very weak.- } \\
\text { Trace. } \\
\text { Trace.....- }\end{array}$ & $\begin{array}{l}\text { Weak } \\
\text { Very weak_- } \\
\text { Faint trace_- } \\
\text { None_...-- }\end{array}$ & $\begin{array}{l}\text { Trace. } \\
\text { Very weak. } \\
\text { None. } \\
\text { None. }\end{array}$ \\
\hline
\end{tabular}

These results indicate that the commercially purified product contained more impurities and greater amounts of each impurity than were in the product of the pilot run. Part of this contamination was believed to result from particles of foreign matter in the commercially refined crystals. When these crystals were dissolved in 10:1 nitric acid, there usually remained a small residue of particles of grit or of iron oxide, with an occasional particle resembling a small bit of porcelain. Filtration of the hot strongly acid solution was not practicable, but the residue could be largely eliminated by allowing the solution to stand for a few minutes and then siphoning off the clear solution. Spectrochemical examination of the products of recrystallization from such a solution showed that a single recrystallization improved the purity and that the purity of the product of a second recrystallization was approaching the limits of determination by that method of analysis. The presence of only two elements could be detected spectrochemically and these "traces" of calcium and silicon were estimated to be small. ${ }^{3}$ Consequently, it was decided to subject an appreciable portion of the ferric nitrate to two recrystallizations, on the assumption that the product would be of satisfactory purity for our purposes. It was further decided to subject another portion to four recrystallizations, in the hope that additional purification might be attained thereby.

\footnotetext{
${ }^{3}$ It was not known until later, when more accurate quantitative calibration of the spectochemical data was available, that spectroscopic traces of silicon might represent as much as 0.01 percent by weight.
} 
At this point it became necessary to suspend operations for approximately 1 year. When operations were resumed it was found that the nitrate crystals had become further contaminated by bits of enamel and iron rust from the enameled tank in which they were stored. The contamination was particularly evident in the material adjacent to the walls and bottom of the tank. This material was discarded, the rest was hand picked and washed and was then subjected to recrystallization according to the program previously adopted.

Details of the procedure for recrystallization of the nitrate and subsequent conversion to ferric oxide were as follows: a batch of 8 pounds of ferric-nitrate crystals in a covered 4 -liter beaker ${ }^{4}$ was dissolved in $1,650 \mathrm{ml}$ of $10: 1^{5}$ nitric acid $^{6}$ by warming on a steam bath. The beaker was allowed to stand for 15 minutes to permit the sediment to settle. The clear solution was then siphoned off and cooled to $15^{\circ} \mathrm{C}$ or less, in cold water. A seed crystal of ferric nitrate was added and the solution was stirred until crystallization was well under way, at which point stirring was discontinued. When the deposit of crystals on the walls of the beaker had become approximately $1 / 2$ inch thick, the beaker was removed from the cold water. The heat liberated by the exothermic crystallization of ferric nitrate soon softened the crystalline cake so that it could be detached from the walls of the beaker and granulated by means of a large porcelain spatula. The beaker then was returned to the cold water and the process was repeated until crystallization was practically complete, as indicated by the contents of the beaker becoming a very thick slurry of uniform consistency and nearly white. This was transferred to a $25-\mathrm{cm}$ Büchner funnel and filtered through no. 2 Whatman filter paper. ${ }^{7}$ Suction was maintained overnight to remove as much as possible of the mother liquor.

The crystals were next returned to the 4-liter beaker, dissolved in fresh 10:1 acid by warming, and the solution was cooled and allowed to crystallize. The crystals were collected and dried with suction and the process repeated as often as desired. In redissolving each crop of crystals a constant proportion of acid to crystals was maintained by decreasing the amount of acid with each successive crystallization to compensate for the loss of ferric nitrate in the mother liquor of the preceding crystallization. Thus $1,650 \mathrm{ml}$ of acid were used to dissolve the original 8 pounds of ferric nitrate; $1,540 \mathrm{ml}$ to dissolve the first crop of crystals; $1,430 \mathrm{ml}$ for the second crop; and $1,320 \mathrm{ml}$ for the third crop.

The final crop of crystals was dissolved in $1,500 \mathrm{ml}$ of distilled water at the boiling point. The solution was filtered through Whatman filter paper to eliminate traces of insoluble matter and was apportioned equally among four 10-gallon Pyrex carboys, which were then filled with distilled water. Anhydrous ammonia was passed into each carboy until a definite odor of ammonia was detectable and the precipitate of hydrated ferric oxide showed a definite tendency to flocculate. The suspension was allowed to stand overnight, after which the precipitate

- All of the glass apparatus and utensils were Pyrex.

- 10 volumes of concentrated acid plus 1 volume of distilled water.

All of the nitric acid used throughout this procedure was freshly distilled in Pyrex.

7 The cold mother liquor could be filtered through paper without difficulty but the hot concentrated ferric-nitrate solution could not. 
occupied about 15 percent of the volume of the carboy. The clear supernatant liquid was siphoned off as completely as possible, ${ }^{8}$ the carboys were refilled with distilled water, and the precipitate was dispersed throughout the solution by stirring with a stream of dust-free air. The washing by decantation was repeated until the supernatant liquid became slightly turbid instead of being perfectly clear. This condition, which indicated complete removal of ammonium nitrate from the hydrated ferric oxide, usually was attained after five washings.

After the final decantation the residual slurry of water and gelatinous precipitate was transferred to covered beakers and maintained for about 10 hours in a steam bath. This treatment not only reduced the apparent volume of the precipitate by about 75 percent, but also transformed it from a gelatinous condition to a relatively granular material. ${ }^{9}$ The coagulated precipitate was filtered in a Büchner funnel with suction and was washed with boiling water. The filter medium consisted of bolting silk and a double thickness of filter paper. The hydrated ferric oxide, even after the coagulation treatment, adhered tightly to filter paper but could be readily separated from bolting silk. The filter cake was dried in an electric oven at about $150^{\circ} \mathrm{C}$. After drying, the friable cake was placed in a glazed porcelain mortar and gently crushed with a porcelain pestle, without grinding. The product was combined with other lots of oxide of similar history.

The supply of purified ferric oxide thus obtained was separated into four lots, as follows:

Lot $A$ represented two laboratory recrystallizations of the crystals from the large-scale crystallizations.

Lot $B$ represented four laboratory recrystallizations of crystals.

Lot $C$ represented two laboratory recrystallizations of the crystals that were recovered from the mother liquor in the large-scale crystallizations.

Lot $D$ represented four laboratory recrystallizations of the crystals recovered from the mother liquor.

Each lot was thoroughly mixed and sampled for analysis. The arc spectra, using carbon electrodes for the region from 2470 to $3390 \mathrm{~A}$ and copper electrodes for the region from 2800 to $4800 \mathrm{~A}$, were examined for the sensitive lines of 49 elements. Chemical analysis was employed to search for two additional elements, sulphur and phosphorus, that are not readily detectable by spectrochemical methods, and to confirm the spectrochemical evidence that only one element, silicon, was present in determinable amounts. The results obtained by the two analytical methods are shown in table 1.

\footnotetext{
8 If the surface of the hydrated ferric oxide was disturbed during settling, by means of a small stream of distilled water, a depression remained in the surface of the fully settled precipitate. Inserting the tip of the siphon in this depression permitted practically complete removal of the supernatant liquid without loss of precipitate.

o This coagulation in the steam bath was not applicable to hydrated ferric oxide precipitated from more concentrated solutions. In one attempt to accelerate the process, four times the usual quantity of ferricnitrate crystals was taken. No difficulty was encountered in the recrystallization process nor in the precipitation, settling and washing of the hydrated ferric oxide in the carboys. Each carboy contained four times the usual amount of hydrated ferric oxide, but there was apparently no difficulty in washing the precipitate free from ammonium nitrate, although more washings than usual were required. However, after the washings were completed, this lot of hydrated oxide could not be coagulated, but remained gelatinous and nonfilterable in spite of extended treatments in the steam bath and additions of small amounts of coagulants including ammonia, nitric acid, and ammonium nitrate. Apparently this hydrated ferric oxide differs appreciably from the products from identical sources but precipitated from a less concentrated solution. Subsequent work was limited to batches of 8 pounds of ferric nitrate, and no further difficulties in coagulation were encountered.
} 
TABLE 1.-Composition of purified iron oxide

\begin{tabular}{|c|c|c|c|c|}
\hline Element & Oxide $A$ & Oxide $B$ & Oxide $C$ & Oxide $D$ \\
\hline $\begin{array}{l}\text { Silicon } \\
\text { Aluminum. } \\
\text { Calcium } \\
\text { Magnesium } \\
\text { Copper } \\
\text { Ag, As, Au, B, Ba, Be, } \\
\text { Bi, Cb, Cd, Ce, Co, } \\
\text { Cr, Ga, Ge, Hf, Hg, } \\
\text { In, Ir, K, Li, Mn, } \\
\text { Mo, Na, Ni, Os, Pb, } \\
\text { Pd, Pt, Rh, Ru, Sb, } \\
\text { Sc, Sn, Sr, Ta, Th, } \\
\text { Ti, Tl, U, V, W, Y, } \\
\text { Zn, Zr. } \\
\text { Sulphur. } \\
\text { Phosphorus........... }\end{array}$ & $\begin{array}{l}\text { Not detected.... } \\
\text { (Not detected) }{ }^{a}- \\
\text { (Not detected) }\end{array}$ & 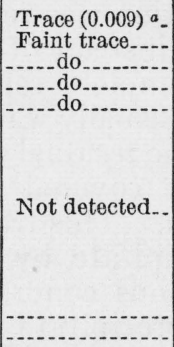 & $\begin{array}{l}\text { Faint trace }(0.006)^{a} \\
\text { Faint trace } \\
\\
\end{array}$ & $\begin{array}{l}\text { Faint trace (0.005). }{ }^{\circ} \\
\text { Faint trace. } \\
\text { do. } \\
\text { do. } \\
\text { do. }\end{array}$ \\
\hline
\end{tabular}

a Data in parentheses are the results of chemical analysis; the limits of sensitivity of the methods employed were 0.001 percent of sulphur and 0.0005 percent of phosphorus. Spectrochemical terms are not comparable for different elements; a faint trace of silicon, for which the spectroscope is relatively insensitive, is 0.006 percent, but faint traces of aluminum, calcium, magnesium, and copper represent much less than 0.001 percent.

These data show that silicon alone is present in amounts that represent appreciable contamination; the sum of all impurities, except silicon, is estimated by the spectroscopist to be less than 0.002 percent for oxide $A$ and less than 0.001 percent for oxides $B, C$, and $D$.

The high silicon contents of oxides $A$ and $B$ are the result of contamination introduced during the commercial purification of ferric nitrate. Iron oxide from a composite sample of the nitrate as received had a silicon content of 0.018 percent, whereas the silicon content of the electrolytic iron was about half that amount. It has been previously mentioned that the primary crystals, from which oxides $A$ and $B$ were prepared, on solution in 10:1 nitric acid showed a small amount of gritty, insoluble residue, including an occasional particle that resembled porcelain. On the other hand, the crystals that were recovered from the mother liquor in the large-scale operations did not show any insoluble residue when they were dissolved in 10:1 acid in preparing the low-silicon oxides $C$ and $D$. The silicon contents of oxides $C$ and $D$ are about the same despite the additional recrystallizations employed in preparing oxide $D$, which indicates that the recrystallization process is not an efficient method for the elimination of silicon. If the silicon contents of oxides $C$ and $D$ represented contamination from dust particles or fly ash, or from impurities in the reagents used, the amounts of associated impurities should be roughly proportional to the silicon content. This is not the case; in each of the oxides the amount of silicon is much greater than the sum of all other impurities. The failure of the recrystallization process to eliminate silicon should have been investigated more thoroughly in the preliminary work, but at that time it was assumed that a spectrochemical trace of silicon was an unimportant and probably negligible amount.

The ajm of this investigation was the production of iron oxide containing a minimum number of impurities with no impurity present in amounts in excess of 0.002 percent. This goal has been achieved except for the silicon contents. The latter, although disappointingly high for the purposes intended, are too small to offer much hope of their reduction or elimination from the oxide by mechanical means or 
chemical treatment. Microscopic examination of the oxides revealed the presence of an occasional, minute particle with a refractive index approximately that of silica or a silicate, but these particles are too small and too few to permit their separation from the mass of ferric oxide. However, according to the evidence of Adcock and Bristow [14], there is at least a possibility that these silicon contents can be reduced by slagging in the reduction of the ferric oxide and subsequent melting of the sponge iron. The investigation of this possibility will be discussed in a future paper.

The authors express their indebtedness to many members of the Bureau staff for advice and assistance in this investigation, and particularly to Bourdon F. Scribner for the spectrochemical analyses, without which the work could not have been completed.

\section{SELECTED REFERENCES}

[1] Rep. Brit. Assn. Adv. Sci. 1868, 342; 1869, 82. Also Chem. News 20, 101 (1869).

[2] Pharm. J, and Trans. 2, 988 (1872).

[3] Ind. and Iron $\mathbf{2 1}, 69$ (1896).

[4] Proc. Am. Acad. Arts. Sei. 35, 253 (1900).

[5] Annual Reports of the Physikalisch-Technische Reichsanstalt. (1905 to 1909, Julius Springer, Berlin.)

[6] Verhand. deut. phys. Ges. 10, 344 (1908).

[7] J. Chem. Soc. 9\%, 2426 (1910).

[8] J. Am. Chem. Soc. 34, 1657 (1912).

[9] Bul. BS 13, 1 (1916-17). S266.

[10] Trans. Am. Soc. Steel Treating 10, 839 (1926).

[11] Z. Elektrochem. 40, 303 (1934).

[12] Engineering 138, 150 (1934).

[13] Proc. Inst. Mech. Eng. 12\%, 277 (1934).

[14] Proc. Roy. Soc. (London) [A] 153, 172 (1935).

[15] The Metal-Iron. (McGraw-Hill Book Co., Inc., New York, N. Y., 1935).

[16] J. Research NBS 16, 105 (1936). RP860.

Washington, February 2, 1937. 